CLINICAL STUDY

\title{
Atorvastatin administration is associated with dose-related changes in IGF bioavailability
}

\author{
Ram P Narayanan, Matthew Gittins ${ }^{1}$, Kirk W Siddals, Robert L Oliver, Julie E Hudson, Anne White ${ }^{2}$, \\ Paul Durrington ${ }^{3}$, Robert R Davies ${ }^{4}$, Martin K Rutter ${ }^{2,4, *}$ and J Martin Gibson* \\ Vascular Research Group, Salford Royal Hospital NHS Foundation Trust, The University of Manchester, B-202, Clinical Sciences Building, Stott Lane, \\ Salford M6 8HD, UK, ${ }^{1}$ Department of Statistics, School of Medicine, The University of Manchester, Oxford Road, Manchester M13 9PL, UK, \\ ${ }^{2}$ Endocrinology and Diabetes Group, Faculty of Medical, Human and Life Sciences, The University of Manchester, Oxford Road, Manchester M13 9PT, UK, \\ ${ }^{3}$ Cardiovascular Research Group, The University of Manchester, Oxford Road, Manchester M13 9NT, UK and ${ }^{4}$ Manchester Diabetes Centre, Central \\ Manchester University Hospital NHS Foundation Trust, Manchester M13 OJE, UK
}

(Correspondence should be addressed to R P Narayanan; Email: ram.narayanan@manchesterac.uk)

*(M K Rutter and J M Gibson share joint last authorship)

\begin{abstract}
Objective: IGF levels, their binding proteins (IGFBPs) and high-dose statin therapy have been linked to the development of diabetes. We aimed to identify whether atorvastatin caused dose-related changes in IGF proteins.

Design and methods: We measured IGF1, IGF2, IGFBP1 and IGFBP3 concentrations at baseline, 6 and 12 months in Protection Against Nephropathy in Diabetes with Atorvastatin trial participants with type 2 diabetes randomised to $10 \mathrm{mg}(n=59)$ vs $80 \mathrm{mg}(n=60)$ of atorvastatin $(n=119$; mean (s.D.): age 64 (10) years; 83\% male; HbA1c 61 (10) $\mathrm{mmol} / \mathrm{mol}$; blood pressure 131/73 $\mathrm{mmHg}$ ).

Results: Atorvastatin was associated with overall reductions in circulating IGF1, IGF2 and IGFBP3 concentrations $(P<0.05$ for all changes). The adjusted mean $(95 \% \mathrm{CI})$ between-group differences that indicate dose-related changes in IGF proteins were not significant for IGF1: $-3(-21$ to 14$) \mathrm{ng} / \mathrm{ml}$; IGF2: -23 ( -65 to 18$) \mathrm{ng} / \mathrm{ml}$ and IGFBP3: $-0.34(-0.71$ to 0.03$) \mu \mathrm{g} / \mathrm{ml}$, negative values indicating numerically greater lowering with high dose. The IGFBP1 concentration did not change with atorvastatin therapy overall but the adjusted mean $(95 \% \mathrm{CI})$ between-group difference indicating a dose-related change in log IGFBP1 was highly significant $-0.41(-0.69$ to $0.13, P=0.004)$. Conclusion: IGF1, IGF2 and IGFBP3 concentrations decreased following atorvastatin therapy. A differential effect of low- vs high-dose atorvastatin on IGFBP1 concentrations was observed with likely implications for IGF bioavailability. The dose-related differential impact of atorvastatin treatment on concentration of IGF proteins merits investigation as a mechanism to explain the worsening of glucose tolerance with statin therapy.
\end{abstract}

European Journal of Endocrinology 168 543-548

\section{Introduction}

3-hydroxy-3-methylglutaryl coenzyme A inhibitors (statins) have an established role in the prevention of cardiovascular disease (1). However, recent studies suggest that high-dose statin therapy may be associated with a small but significant increase in the risk of type 2 diabetes through unknown mechanisms (2). The ligands IGF1 and IGF2 have structural and functional homologies with insulin and their downstream signalling pathways have many commonalities with that of insulin (3). Low IGF1 concentration has been linked with increased rates of glucose intolerance and type 2 diabetes $(4,5,6)$, though there are some suggestions that high IGF1 levels may also be related to an increase in diabetes incidence (7). Polymorphisms in the IGF1 gene have been associated with fasting insulin in genome-wide association studies (8).

IGF2 is critical in embryonic growth and development but its post-natal roles are less clear. IGF2 signalling can occur through the insulin receptors, and excessive IGF2 production in neoplasms is known to cause hypoglycaemia (9).

IGF binding protein 1 (IGFBP1) is an acute modulator of IGF1 and IGF2 bioavailability, and altered IGFBP1 levels have also been linked to diabetes rates $(10,11,12)$. IGFBP 3 is the principal carrier protein of IGF1 and IGF 2. In vitro studies suggest that statins have profound effects on insulin and IGF1 signalling (13). The aim of our study was to identify dose-related changes in the circulating levels of IGFs and their major binding proteins with statin therapy in patients with type 2 diabetes. 


\section{Materials and methods}

\section{Subjects}

We studied individuals in the Protection Against Nephropathy in Diabetes with Atorvastatin (PANDA) study that has been previously described (14). Briefly, participants were $>40$ years with type 2 diabetes and microalbuminuria recruited from four secondary care-based diabetes clinics in Manchester, UK. Exclusion criteria included pregnancy, proteinuria $>2 \mathrm{~g} /$ day, serum creatinine $>200 \mu \mathrm{mol} / \mathrm{l}$, blood pressure $>160 / 90 \mathrm{mmHg}$ at randomisation, serum cholesterol $>7 \mathrm{mmol} / \mathrm{l}$, abnormal liver function, $\mathrm{HbA} 1 \mathrm{c}>86 \mathrm{mmol} / \mathrm{mol}$ (10\%), untreated hypothyroidism, intolerance of statin or angiotensin II receptorblocking drugs, subjects taking atorvastatin doses $>10 \mathrm{mg}$ daily or the equivalent doses of other statins, use of any non-statin lipid-lowering agent or the presence of any illness that could affect the trial.

After a statin washout period of up to 2-week duration, patients were randomised to either 10 or $80 \mathrm{mg}(2 \times 40 \mathrm{mg}$ tablets $)$ atorvastatin including matching placebo tablets in a double-blind fashion. Placebo tablets were used so that patients in the lowand high-dose groups received the same number of identical tablets. The study was approved by the local research ethics committee, informed consent was obtained from all patients and investigations were carried out in accordance with the principles of the Declaration of Helsinki as revised in 2000.

\section{Laboratory measurements}

Analysis of fasting IGF1, IGF2, IGFBP1 and IGFBP3 was performed on blood samples drawn at baseline, 6 and
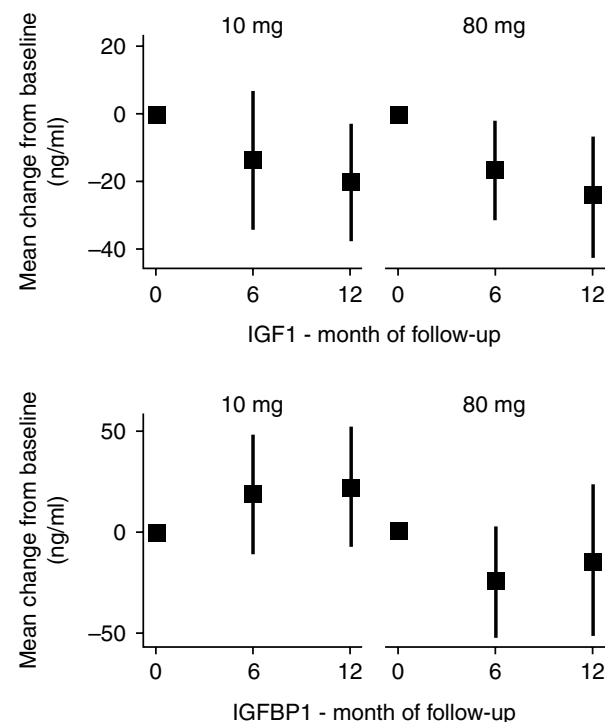

12 months. Plasma IGF1 and IGFBP3 were measured using an Immulite 1000 Immunoassay system (Siemens Healthcare Diagnostics, Inc., Tarrytown, NY, USA), utilising an enzyme-labelled chemiluminescent immunometric assay. Serum IGF2 was measured using a locally developed two-site extraction-based ELISA using antibodies that have been previously reported (15). Plasma IGFBP1 was measured using a locally developed two-site ELISA that can detect all phosphoisoforms of this protein. MABs 6301 (capture antibody) and 6303 (detection antibody) were obtained from Medix Biochemica (Kauniainen, Finland). The analytical sensitivities, inter-assay and intra-assay coefficients of variation for the assays were IGF1: $20 \mathrm{ng} / \mathrm{ml}$, $<8.4 \%, \quad<4.5 \%$; IGF 2 : $5 \mathrm{ng} / \mathrm{ml}, \quad<9.2 \%, \quad<9.2 \%$; IGFBP1: $0.1 \mathrm{ng} / \mathrm{ml}, \quad<7 \%,<9.4 \%$; and IGFBP3: $0.1 \mu \mathrm{g} / \mathrm{l},<10 \%$ and $<6 \%$ respectively.

\section{Statistical analyses}

A log-transformation of the skewed IGFBP1 values meant that assumptions of normality were maintained and parametric tests were used throughout. In order to estimate for IGF1 bioavailability, molar ratios of IGF1:IGFBP1 and IGF1:IGFBP3 were included in their analysis. Unadjusted mean $(95 \% \mathrm{CI})$ within-individual change from baseline to 12 months in IGF1, IGF2 and the binding protein levels was calculated for high- and low-dose atorvastatin groups (Fig. 1). The main endpoint of the study was the differential effects of high- vs low-dose atorvastatin on concentrations of plasma IGF1, serum IGF2, plasma IGFBP1 and plasma IGFBP3 over a 12-month period. A linear mixed-effects model was used to calculate the effect of atorvastatin dose (10 vs $80 \mathrm{mg}$ ) on circulating levels of the four IGF
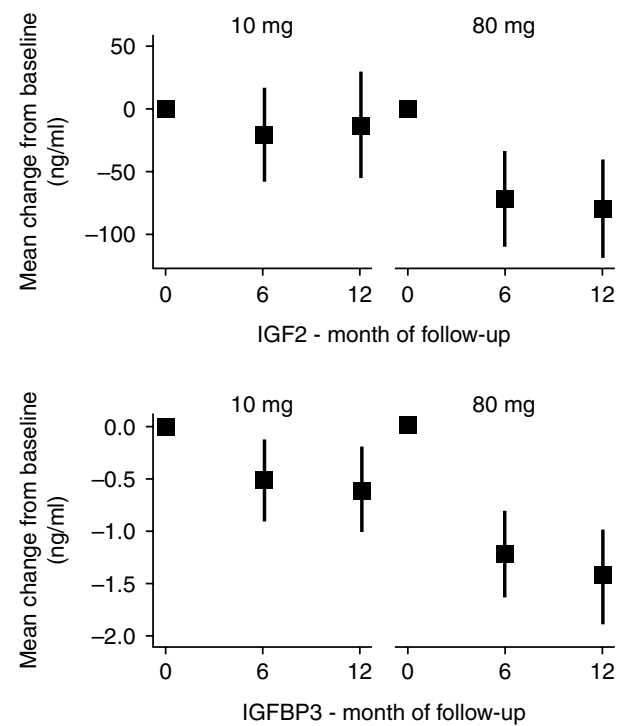

Figure 1 Mean change in IGF1, IGF2, IGFBP1 and IGFBP3 concentrations from baseline in subjects treated with 10 and 80 mg atorvastatin.

www.eje-online.org 
proteins across longitudinal data collected at $\sim 6$ and 12 months. In each analysis, these levels were adjusted for the following covariates defined a priori: mean centred time, age, gender, baseline measurements of the IGF proteins, BMI and the use of insulin and statins before randomisation. In each case, an interaction term, mean centred time and atorvastatin dose with respect to any of the proteins measured was found to be nonsignificant and removed from the model. Accordingly, the analysis was configured to identify the differential impact of the $80 \mathrm{mg}$ dose of atorvastatin compared with the $10 \mathrm{mg}$ dose on each of the IGF proteins. All analyses were performed using Stata 11 (Statacorp., College Station, TX, USA). Two-tailed $P<0.05$ was considered statistically significant.

\section{Results}

Clinical characteristics of the study population at randomisation are shown in Table 1. As previously described, those randomised to high- vs low-dose atorvastatin were similar with respect to age, gender, microalbuminuria, hypertension and glycaemic control at randomisation (14). A high proportion of participants in both the high- and low-dose atorvastatin study groups had a statin washout period that was up to 2 weeks in duration. We excluded one subject from analysis who had biologically implausible results.

The baseline concentrations of the IGF proteins in the high- and low-dose treatment groups are shown in Table 2 (columns 2 and 3), and the changes in each of these at 6 and 12 months are shown in Fig. 1. Atorvastatin therapy was associated with significant

Table 1 Baseline clinical characteristics at randomisation by treatment group. Data are mean (s.D.) or \%, unless stated. Hypertension was defined as BP $>130 / 80 \mathrm{mmHg}$ or anti-hypertensive therapy.

\begin{tabular}{lll}
\hline Baseline characteristic & $\begin{array}{l}\text { Atorvastatin } \\
10 \mathrm{mg}\end{array}$ & $\begin{array}{l}\text { Atorvastatin } \\
80 \mathrm{mg}\end{array}$ \\
\hline$n$ & 59 & 60 \\
Age (years) & $65(10)$ & $63.5(9.5)$ \\
Male (\%) & 81 & 85 \\
Hypertension (\%) & 98 & 96 \\
Diabetes duration (years) & $12.6(8.7)$ & $11.1(7.8)$ \\
BMI (kg/m ${ }^{2}$ ) & $32(29-35)$ & $34(28-38)$ \\
Diabetes therapy & & 40 \\
Oral hypoglycaemic agents (\%) & 48 & 10 \\
Insulin only (\%) & 14 & 43 \\
Insulin and OHA (\%) & 32 & $72(54-85)$ \\
MDRD eGFR (ml/min per & $61(44-76)$ & \\
1.73 m²) & & $5.2(1.1)$ \\
Total cholesterol (mmol/l) & $5.1(1.0)$ & $7.6(1.4)$ \\
HbA1c (\%) & $7.8(1.2)$ & $60(8)$ \\
HbA1c (mmol/mol) & $62(10)$ & 97 \\
Statin washout period of up to & 90 & \\
2 weeks (\%) & & \\
\hline
\end{tabular}

MDRD eGFR, modification of diet in renal disease-estimated glomerular filtration rate; $\mathrm{OHA}$, oral hypoglycaemic agents. reductions in circulating levels of IGF1, IGF2 and IGFBP3 when groups taking low- and high-dose atorvastatin were combined. The unadjusted mean (95\% CI) change in IGF proteins for combined low- and high-dose atorvastatin groups were IGF1: $-22(-35$ to -10$) \mathrm{ng} / \mathrm{ml}$; IGF2: $-46(-75$ to -16$) \mathrm{ng} / \mathrm{ml}$ and IGFBP3: $-1.0(-1.3$ to -0.7$) \mathrm{mg} / \mathrm{l}(P<0.05$ for all changes; Table 2). The corresponding data for IGFBP1 were 5 ( -19 to 29$) \mathrm{ng} / \mathrm{ml}, P=\mathrm{NS}$. The concentration of IGFBP1 was reduced in subjects receiving high-dose atorvastatin but was increased from baseline with lowdose therapy (Fig. 1). However, we did not assess the statistical significance of within-group changes because the results may have been misleading due to the absence of a placebo-only-treated group.

Table 2 (columns 5 and 6) shows the results of the mixed-effects longitudinal model in which betweengroup differences over 12 months were adjusted for baseline levels of each biomarker, age, sex, BMI and the use of statin washout period and use of insulin therapy at baseline. The adjusted mean (95\% CI) between-group difference in log-IGFBP1 was highly significant $(-0.41$ $(-0.69$ to -0.13$), P=0.004)$. In these analyses, negative values indicate numerically higher lowering of IGF values with $80 \mathrm{mg}$ dose compared with the $10 \mathrm{mg}$ dose. The corresponding data for IGFBP1 without log-transformation was also statistically significant (adjusted mean (95\% CI) between-group difference in IGFBP1: $-37(-68$ to -6$), P=0.02)$. These data are presented in Table 2 for comparison with other unadjusted data (i.e. not adjusted for baseline levels of each biomarker, age, sex, BMI and the use of a statin washout period and use of insulin therapy at baseline). There was a corresponding significant increase in IGF1/IGFBP1 ratio: mean (95\% CI) 7 (1 to 12), $P=0.02$. Here, a positive value indicates that subjects on $80 \mathrm{mg}$ atorvastatin had higher mean IGF1/IGFBP1 ratio values during follow-up compared with subjects on the $10 \mathrm{mg}$ dose of atorvastatin. The adjusted mean (95\% CI) between-group difference in IGF proteins between the high- and low-dose atorvastatin treatment groups was not significant for IGF1 $(-3$ $(-20$ to 14$))$, IGF2 ( -23 ( -65 to 18$)$ ) and IGFBP3 $(-0.34(-0.71$ to 0.03$))$. There was no correlation between change in HbA1c and IGFBP1 (or any of the other measured IGF proteins) over the 12-month period of this study.

\section{Discussion}

Here, we present the first study demonstrating the effects of different statin doses on longitudinal trends in IGFs and their binding proteins. The observed changes are important because changes in IGF bioavailability have known associations with diabetes incidence, and higher rates of incident diabetes have been observed with high-dose statin therapy (2). 
Table 2 IGF endpoints: baseline data, unadjusted 12-month change for combined groups and adjusted mean (95\% CI) differences between high- and low-dose atorvastatin groups over the 12-month follow-up period. Baseline data are mean (s.D.) or median (IQR). Change and difference data are mean $(95 \% \mathrm{Cl})$ values. Data are adjusted for baseline level of IGF molecule, age, sex, BMI, use of insulin therapy and use of a washout period. A negative value for adjusted mean difference indicates that patients receiving atorvastatin $80 \mathrm{mg}$ daily had lower average values during follow-up than those receiving $10 \mathrm{mg}$ daily. For example, IGF1 levels were $3 \mathrm{mmol} / \mathrm{l}$ lower $(P=0.72)$ during follow-up in patients taking atorvastatin $80 \mathrm{mg}$ daily compared with those taking $10 \mathrm{mg}$ daily. A positive value for adjusted mean difference indicates that patients receiving atorvastatin $80 \mathrm{mg}$ daily had higher average values during follow-up than those receiving $10 \mathrm{mg}$ daily. The number of patient samples available for each analysis: $10 \mathrm{mg}$ daily dose: 50-52 patients; $80 \mathrm{mg}$ daily dose 50-51 patients. Mean (inter-quartile range) follow-up was 12.0 (11.7-12.4) months.

\begin{tabular}{|c|c|c|c|c|c|}
\hline Biomarker & $\begin{array}{l}\text { Baseline value in } \\
\text { atorvastatin } 10 \mathrm{mg} \\
\text { daily group }(n=59)\end{array}$ & $\begin{array}{l}\text { Baseline value in } \\
\text { atorvastatin } 80 \mathrm{mg} \\
\text { daily group }(n=60)\end{array}$ & $\begin{array}{l}\text { Unadjusted mean } \\
(95 \% \mathrm{Cl}) \text { change } \\
\text { between final visit and } \\
\text { baseline for all patients } \\
\text { (10 mg and } 80 \mathrm{mg} / \mathrm{day} \\
\text { groups combined })\end{array}$ & $\begin{array}{l}\text { Adjusted mean } \\
(95 \% \mathrm{Cl}) \text { difference } \\
\text { between high- and low- } \\
\text { dose groups over } 12 \\
\text { months of follow-up }\end{array}$ & $\begin{array}{c}P \text { value for } \\
\text { adjusted mean } \\
\text { difference between } \\
\text { groups during } \\
\text { follow-up, adjusted } \\
\text { for baseline } \\
\text { differences }\end{array}$ \\
\hline IGF1 (ng/ml) & $154(61)$ & $152(62)$ & $-22(-35 \text { to }-10)^{*}$ & $-3(-20$ to 14$)$ & 0.72 \\
\hline IGF2 (ng/ml) & $461(156)$ & 504 (165) & $-46(-75 \text { to }-16)^{*}$ & $-23(-65$ to 18$)$ & 0.27 \\
\hline IGFBP1 (ng/ml) & 74 (29 to 142$)$ & 54 (32 to 113 ) & $5(-19$ to 29$)$ & $-37(-68$ to -6$)$ & 0.02 \\
\hline IGFBP3 (mg/l) & $4.5(1.4)$ & $4.9(1.7)$ & $-1.0(-1.3 \text { to }-0.7)^{*}$ & $-0.34(-0.71$ to 0.03$)$ & 0.07 \\
\hline IGF1/IGFBP1 & $14(16)$ & $17(31)$ & $0(-5$ to 4$)$ & 7 ( 1 to 12$)$ & 0.02 \\
\hline IGF1/IGFBP3 & $0.2(0.06)$ & $0.2(0.06)$ & $0.01(-0.00$ to 0.02$)$ & $0.01(-0.01$ to 0.02$)$ & 0.48 \\
\hline
\end{tabular}

${ }^{*} P<0.05$.

\section{Main findings}

We showed that atorvastatin therapy overall (low- and high-dose atorvastatin combined) was associated with a decrease in IGF1, IGF2 and IGFBP3 levels. We have also demonstrated a dose-dependent effect of atorvastatin on plasma IGFBP1 concentration. Low-dose atorvastatin therapy increased IGFBP1 levels, while high-dose treatment resulted in a decrease.

\section{IGFBP1 system in health and disease}

IGF1 and IGF2 are potent anabolic factors that are fundamental to growth, development and metabolism (3). Both peptides have significant structural homology with insulin and share similar downstream signalling pathways, suggesting a role in glucose homoeostasis $(16,17)$.

The biological actions of IGF1 and IGF2 are determined by their interactions with six binding proteins, described as IGFBP1 to IGFBP6. IGFBP1 is the principal acute regulator of IGF1 biological actions. IGFBP1 is potently and dynamically inhibited by insulin (18), and levels are affected by the diet and prandial state as well as other factors like age and BMI (19). IGFBP1 is a marker of insulin sensitivity (20). In clinical and population studies, low circulating IGFBP1 concentration has been associated with insulin resistance $(11,21)$ and an increased risk for incident gestational diabetes, glucose intolerance and type 2 diabetes $(4,10,11,22)$.

\section{Differential effects of statin dose on IGFBPI and implications for diabetes risk}

Recent meta-analyses have suggested that, when compared with placebo, statin therapy was associated with a 9\% higher risk for incident diabetes (23) and, when compared with low-dose statin therapy, high-dose statin therapy was associated with a further $12 \%$ elevation in risk (2). There is also evidence that statin therapy is associated with worsening glycaemic control in individuals who already have type 2 diabetes (24). On a cellular level, we have previously shown that statins can directly reduce insulin signalling by depleting cells of dolichol, a derivative of mevalonate, which in turn affects insulin receptor processing with the eventual result of fewer, mature, insulin receptors at the cell surface (13). In this study, which involved individuals with type 2 diabetes, an exploratory analysis did show that high-dose atorvastatin was associated with worse glycaemic control at the 2-year follow-up (HbA1c was $2.4 \mathrm{mmol} / \mathrm{l}(0.3 \%)$ higher $(P=0.017))$ after 2 years of high-dose therapy (14), but these differences were not significant at 1 year (not shown).

We showed that compared with the low-dose therapy, high-dose atorvastatin was associated with lowering of IGFBP1 levels, which has been associated with an increased risk for gestational diabetes, glucose tolerance and type 2 diabetes $(4,10,11,22)$. The cause of the dose-dependent effect of atorvastatin on IGFBP1 concentration is unclear. However, as a dose-dependent effect of atorvastatin on insulin resistance has been described (25), it is tempting to speculate that changes in insulin concentration and insulin resistance may be implicated. If high-dose atorvastatin caused greater insulin resistance and hyperinsulinaemia compared with low-dose atorvastatin, then this could suppress hepatic IGFBP1 production and decrease circulating IGFBP1 concentration. As we did not measure insulin levels, we are unable to test this hypothesis. 


\section{Effect on other IGF proteins and implications for diabetes risk}

The majority of our patients had a 2-week statin washout period that was up to 2 weeks in duration. This may have been long enough to allow IGF proteins to return towards normal pre-treatment levels. In our within-group analysis, we showed longitudinal reductions in IGF1, IGF2 and IGFBP3 with both lowand high-dose atorvastatin therapy. The design of our trial means that these data are less robust than our comparison of the low- and high-dose atorvastatin groups. However, these data are in keeping with the results of a study involving 156 patients with hypercholesterolaemia who experienced lowering of IGF1 levels with low-dose simvastatin therapy (26). Although we showed that the effect on these protein concentrations was not dose dependent, the overall fall in insulin-like activity resulting from lower IGF1 and IGF2 concentration could potentially contribute to increased glucose concentrations, perhaps partly mediated by a compensatory elevation in $\mathrm{GH}$. The changes in IGF proteins might go some way to explain the increased risk of incident diabetes in patients receiving statin therapy compared with placebo (23).

\section{Effect on other IGF proteins and implications for cardiovascular and malignancy risk}

Altered concentrations of IGF proteins have been associated not only with subsequent worsening of glucose tolerance but also increased macrovascular risk $(4,12,27,28)$. However, statin therapy unambiguously decreases cardiovascular risk, suggesting that associations of low IGF bioavailability with an adverse cardiovascular profile are not sustained in the presence of statin therapy. Arguably, the cardiovascular benefits of atorvastatin therapy would be even greater without the increased incidence of diabetes.

\section{Strengths and weaknesses}

This is the first study to demonstrate dose-dependent effects of a statin on IGFs and two binding proteins that influence IGF bioavailability. These data are particularly valuable because the patients were well characterised and were involved in a randomised double-blind placebo-controlled clinical trial comparing the clinical effects of different statin doses. The study does have some weaknesses. First, it was a relatively small study with a short duration of follow-up, but nevertheless, we were able to show dose-dependent effects of atorvastatin on the IGF system. However, the limited sample size may explain the lack of significant correlation between changes in IGFBP1 and HbA1c. Secondly, although the study was designed prospectively, this was a post hoc analysis of a trial designed for another purpose - i.e. to assess the effects of statin dose on renal function.
Thirdly, this was a study of patients with type 2 diabetes and albuminuria and therefore the results may have limited generalisability. Fourthly, we did not measure glucose tolerance or insulin resistance that would have helped clarify the underlying pathophysiological mechanisms. Lastly, we performed the study in patients with type 2 diabetes, and therefore, we were not able to relate changes in IGF proteins to incident diabetes.

\section{Clinical implications and future work}

There are no immediate clinical implications of this work, but this is an important area for future research because of the increasing and widespread use of statin medication. Although statins have major health benefits, there is a need to understand the mechanisms behind potential adverse effects so that we might develop ways to mitigate these effects. Our study needs to be replicated in larger and more diverse populations in the first instance.

We report an overall decrease in the concentration of the IGFs with atorvastatin therapy and a dosedependent change in IGFBP1 concentration following atorvastatin administration in patients with type 2 diabetes. The effects of atorvastatin on IGF1, IGF2, IGFBP1 and IGFBP 3 concentration could suggest a possible mechanism linking high-dose 3 hydroxy 3-methylglutaryl coenzyme A reductase inhibitor treatment with higher rates of incident type 2 diabetes.

The online version of this manuscript contains an additional table (Supplementary Table 1, see section on supplementary data given at the end of this article) that represents the mean circulating concentrations of IGF1, IGF2, IGFBP1 and IGFBP 3 at study baseline, 6 months and at study completion (12 months) for study subjects administered $10 \mathrm{mg}$ atorvastatin, $80 \mathrm{mg}$ atorvastatin and for the study population as a whole.

\section{Supplementary data}

This is linked to the online version of the paper at http://dx.doi.org/10. 1530/EJE-12-0844.

\section{Declaration of interest}

J M Gibson and M K Rutter have received travel grants and honoraria for speaking at meetings sponsored by Pfizer. M Gittins's salary has previously been partly funded by research grants from Pfizer. The University and Hospital trusts employing M K Rutter and J M Gibson have received research grants from Pfizer UK. The authors report no other conflicts of interest.

\section{Funding}

The PANDA study was funded by an unrestricted grant from Pfizer UK that markets atorvastatin. The sponsors were allowed to comment on the manuscript but they had no right of veto over any of the contents. This study was supported by the Manchester Academic Health Science Centre (MAHSC) and the Manchester NIHR Biomedical Research Centre. M K Rutter is supported by a HEFCE Clinical Senior Lecturer award. 


\section{References}

1 Baigent C, Keech A, Kearney PM, Blackwell L, Buck G, Pollicino C, Kirby A, Sourjina T, Peto R, Collins R et al. Efficacy and safety of cholesterol-lowering treatment: prospective meta-analysis of data from 90,056 participants in 14 randomised trials of statins. Lancet $2005 \mathbf{3 6 6}$ 1267-1278. (doi:10.1016/S0140-6736(05)67394-1)

2 Preiss D, Seshasai SRK, Welsh P, Murphy SA, Ho JE, Waters DD, DeMicco DA, Barter P, Cannon CP, Sabatine MS et al. Risk of incident diabetes with intensive-dose compared with moderatedose statin therapy: a meta-analysis. Journal of the American Medical Association 2011305 2556-2564. (doi:10.1001/jama. 2011.860)

3 Jones JI \& Clemmons DR. Insulin-like growth factors and their binding proteins: biological actions. Endocrine Reviews 1995 16 3-34. (doi:10.1210/edrv-16-1-3)

4 Sandhu MS, Heald AH, Gibson JM, Cruickshank JK, Dunger DB \& Wareham NJ. Circulating concentrations of insulin-like growth factor-I and development of glucose intolerance: a prospective observational study. Lancet 2002359 1740-1745. (doi:10.1016/ S0140-6736(02)08655-5)

5 Wallander M, Brismar K, Ohrvik J, Ryden L \& Norhammar A. Insulinlike growth factor I: a predictor of long-term glucose abnormalities in patients with acute myocardial infarction. Diabetologia $2006 \mathbf{4 9}$ 2247-2255. (doi:10.1007/s00125-006-0386-1)

6 Teppala S \& Shankar A. Association between serum IGF-1 and diabetes among U.S. adults. Diabetes Care 201033 2257-2259. (doi:10.2337/dc10-0770)

7 Schneider HJ, Friedrich N, Klotsche J, Schipf S, Nauck M, Valzke H, Sievers C, Pieper L, Morz W, Wittchen H-U et al. Prediction of incident diabetes mellitus by baseline IGF1 levels. European Journal of Endocrinology 2011164 223-229. (doi:10.1530/EJE-10-0963)

8 Dupuis J, Langenberg C, Prokopenko I, Saxena R, Soranzo N, Jackson AU, Wheeler E, Glazer NL, Bouatia-Naji N, Gloyn AL et al. New genetic loci implicated in fasting glucose homeostasis and their impact on type 2 diabetes risk. Nature Genetics 201042105 116. (doi:10.1038/ng.520)

9 Hill D, Livingstone K, Thomson JE, Perry C \& Wark G. IGF-II secreting solitary fibrous tumour of the liver presenting with hypoglycaemia. Scottish Medical Journal 200853 60-61. (doi:10. 1258/rsmsmj.53.1.60c)

10 Petersson U, Ostgren CJ, Brudin L, Brismar K \& Nilsson PM. Low levels of insulin-like growth-factor-binding protein-1 (IGFBP-1) are prospectively associated with the incidence of type 2 diabetes and impaired glucose tolerance (IGT): the Soderakra Cardiovascular Risk Factor Study. Diabetes $\mathcal{E}$ Metabolism 200935 198-205. (doi:10.1016/j.diabet.2008.11.003)

11 Lewitt MS, Hilding A, Ostenson CG, Efendic S, Brismar K \& Hall K. Insulin-like growth factor-binding protein-1 in the prediction and development of type 2 diabetes in middle-aged Swedish men. Diabetologia 200851 1135-1145. (doi:10.1007/s00125-008-1016-x)

12 Heald AH, Cruickshank JK, Riste LK, Cade JE, Anderson S, Greenhalgh A, Sampayo J, Taylor W, Fraser W, White A et al. Close relation of fasting insulin-like growth factor binding protein-1 (IGFBP-1) with glucose tolerance and cardiovascular risk in two populations. Diabetologia $2001 \quad 44$ 333-339. (doi:10.1007/ s001250051623)

13 Siddals KW, Marshman E, Westwood M \& Gibson JM. Abrogation of insulin-like growth factor-I (IGF-I) and insulin action by mevalonic acid depletion: synergy between protein prenylation and receptor glycosylation pathways. Journal of Biological Chemistry 2004279 38353-38359. (doi:10.1074/jbc.M404838200)

14 Rutter MK, Prais HR, Charlton Menys V, Gittins M, Roberts C, Davies RR, Moorhouse A, Jinadev P, France M, Wiles PG et al. Protection Against Nephropathy in Diabetes with Atorvastatin (PANDA): a randomized double-blind placebo-controlled trial of high- vs. low-dose atorvastatin(1). Diabetic Medicine 201128 100-108. (doi:10.1111/j.1464-5491.2010.03139.x)

15 Crosby SR, Anderton CD, Westwood M, Holly JM, Cwyfan Hughes SC, Gibson M, Morrison CA, Young RJ \& White A.
Measurement of insulin-like growth factor-II in human plasma using a specific monoclonal antibody-based two-site immunoradiometric assay. Journal of Endocrinology 1993137 141-150. (doi:10.1677/joe.0.1370141)

16 Froesch ER \& Zapf J. Insulin-like growth factors and insulin: comparative aspects. Diabetologia 198528 485-493. (doi:10. 1007/BF00281982)

17 Zapf J, Hauri C, Waldvogel M \& Froesch ER. Acute metabolic effects and half-lives of intravenously administered insulin-like growth factors I and II in normal and hypophysectomized rats. Journal of Clinical Investigation $1986 \quad 77 \quad 1768-1775 . \quad$ (doi:10.1172/ JCI112500)

18 Conover CA \& Lee PD. Insulin regulation of insulin-like growth factor-binding protein production in cultured HepG2 cells. Journal of Clinical Endocrinology and Metabolism $1990 \mathbf{7 0} 1062$ 1067. (doi:10.1210/jcem-70-4-1062)

19 Weaver JU, Holly JM, Kopelman PG, Noonan K, Giadom CG, White N, Virdee S \& Wass JA. Decreased sex hormone binding globulin (SHBG) and insulin-like growth factor binding protein (IGFBP-1) in extreme obesity. Clinical Endocrinology 199033 415422. (doi:10.1111/j.1365-2265.1990.tb00507.x)

20 Kotronen A, Lewitt M, Hall K, Brismar K \& Yki-Jarvinen H. Insulin-like growth factor binding protein 1 as a novel specific marker of hepatic insulin sensitivity. Journal of Clinical Endocrinology and Metabolism 200893 4867-4872. (doi:10.1210/jc. 2008-1245)

21 Lewitt MS, Hilding A, Brismar K, Efendic S, Ostenson C-G \& Hall K. IGF-binding protein 1 and abdominal obesity in the development of type 2 diabetes in women. European Journal of Endocrinology 2010163 233-242. (doi:10.1530/EJE-10-0301)

22 Oiu C, Vadachkoria S, Meryman L, Frederick IO \& Williams MA. Maternal plasma concentrations of IGF-1, IGFBP-1, and C-peptide in early pregnancy and subsequent risk of gestational diabetes mellitus. American Journal of Obstetrics and Gynecology 2005193 1691-1697. (doi:10.1016/j.ajog.2005.04.015)

23 Sattar N, Preiss D, Murray HM, Welsh P, Buckley BM, de Craen AJM, Seshasai SRK, McMurray JJ, Freeman DJ, Jukema JW et al. Statins and risk of incident diabetes: a collaborative metaanalysis of randomised statin trials. Lancet 2010375 735-742. (doi:10.1016/S0140-6736(09)61965-6)

24 Betteridge DJ \& Gibson JM. Effects of rosuvastatin on lipids, lipoproteins and apolipoproteins in the dyslipidaemia of diabetes. Diabetic Medicine 2007 24 541-549. (doi:10.1111/j.1464-5491. 2007.02095.x)

25 Koh KK, Quon MJ, Han SH, Lee Y, Kim SJ \& Shin EK. Atorvastatin causes insulin resistance and increases ambient glycemia in hypercholesterolemic patients. Journal of the American College of Cardiology 201055 1209-1216. (doi:10.1016/j.jacc.2009.10.053)

26 Szkodzinski J, Romanowski W, Hudzik B, Kaszuba A, Nowakowska-Zajdel E, Szkilnik R, Pietrasinska B \& ZubelewiczSzkodzinska B. Effect of HMG-CoA (3-hydroxy-3-methylglutaryl$\mathrm{CoA}$ ) reductase inhibitors on the concentration of insulin-like growth factor-1 (IGF-1) in hypercholesterolemic patients. Pharmacological Reports: PR 200961 654-664.

27 Heald AH, Siddals KW, Fraser W, Taylor W, Kaushal K, Morris J, Young RJ, White A \& Gibson JM. Low circulating levels of insulinlike growth factor binding protein-1 (IGFBP-1) are closely associated with the presence of macrovascular disease and hypertension in type 2 diabetes. Diabetes 200251 2629-2636. (doi:10.2337/diabetes.51.8.2629)

28 Wallander M, Norhammar A, Malmberg K, Ohrvik J, Ryden L \& Brismar K. IGF binding protein 1 predicts cardiovascular morbidity and mortality in patients with acute myocardial infarction and type 2 diabetes. Diabetes Care 200730 23432348. (doi:10.2337/dc07-0825)

Received 25 September 2012

Revised version received 14 January 2013

Accepted 18 January 2013 